Original Article

\title{
The effect of wearing night splints for one year on the standing motor function of patients with Duchenne muscular dystrophy
}

\author{
Hitomi Nishizawa, RPT, MS ${ }^{1)^{*}}$, Ayumi Matsukiyo, RPT, $\mathrm{PhD}^{2)}$, Naoko Shiba, MD, PhD ${ }^{3)}$, \\ Masayoshi Koinuma, PhD ${ }^{4,5)}$, Akinori NaKamura, MD, $\mathrm{PhD}^{6,7)}$ \\ 1) School of Health Sciences, Faculty of Medicine, Shinshu University: 3-1-1 Asahi, Matsumoto, \\ Nagano 390-8621, Japan \\ 2) Research Center for Advanced Science and Technology Project, The University of Tokyo, Japan \\ 3) Department of Pediatrics, Shinshu University School of Medicine, Japan \\ 4) Center for Clinical Research, Shinshu University Hospital, Japan \\ 5) Faculty of Pharmaceutical Sciences, Teikyo Heisei University, Japan \\ 6) Third Department of Internal Medicine, Shinshu University School of Medicine, Japan \\ 7) Department of Neurology, National Hospital Organization, Matsumoto Medical Center, Japan
}

\begin{abstract}
Purpose] To investigate the effect of night splints on the standing motor function and ankle dorsiflexion angles of patients with Duchenne muscular dystrophy (DMD). [Subjects and Methods] Nine boys (age $<11$ years) with DMD were divided into the sufficiently-wearing group and the insufficiently-wearing group, according to how often they wore their splint for one year. We evaluated the changes between the pre-implementation and the one-year-after assessments of both the sufficiently-wearing group and the insufficiently-wearing group for the ankle dorsiflexion angle, North Star Ambulatory Assessment, 10-m running time, and time to stand from the floor. [Results] Only the left dorsiflexion angle of the ankle showed significantly difference for the sufficiently-wearing group. For other indicators, there were tendency toward improvement and maintenance in the sufficiently-wearing group. [Conclusion] The standing motor function improved significantly in some patients in the sufficiently-wearing group, suggesting that wearing night splints may promote the improvement and/or maintain of standing motor function in patients with DMD.

Key words: Duchenne muscular dystrophy, Night splint, Motor function
\end{abstract}

(This article was submitted Dec. 7, 2017, and was accepted Jan. 17, 2018)

\section{INTRODUCTION}

Duchenne muscular dystrophy (DMD) is an X chromosome-linked disorder that causes progressive muscle atrophy and weakness. It is the most prevalent hereditary muscle disease, occurring in 1 in every 3,600 male births ${ }^{1-3)}$. DMD begins with gait disturbance between the ages of 2 and 5 years. Whole-body muscle atrophy and weakness occur; patients become unable to walk at approximately 13 years of age ${ }^{4)}$ and typically die of respiratory or cardiac failure at approximately 30 years ${ }^{1,5}$.

One of the objectives of physical therapy for patients with DMD is the prevention of ankle joint deformation and maintenance of motor function ${ }^{4}$. In general, it is necessary to maintain the patient's ability to stand in order to maintain their walking ability, but clubfoot has been reported to cause problems ${ }^{5}$. Furthermore, in patients with DMD, clubfoot due to contracture of the ankle is one of the causes of difficulty in standing. The degree of contracture progression was reported to be $0.4^{\circ}$ per month ${ }^{6}$, however, there are few effective treatments for this progression of contracture. In addition, it has been reported that corticosteroids ${ }^{7)}$ and surgical treatments have not been effective for the improvement for the range of motion

*Corresponding author. Hitomi Nishizawa (E-mail: hitnishi@shinshu-u.ac.jp)

(C2018 The Society of Physical Therapy Science. Published by IPEC Inc.

(c) (1) $\odot$ This is an open-access article distributed under the terms of the Creative Commons Attribution Non-Commercial No Deriva-






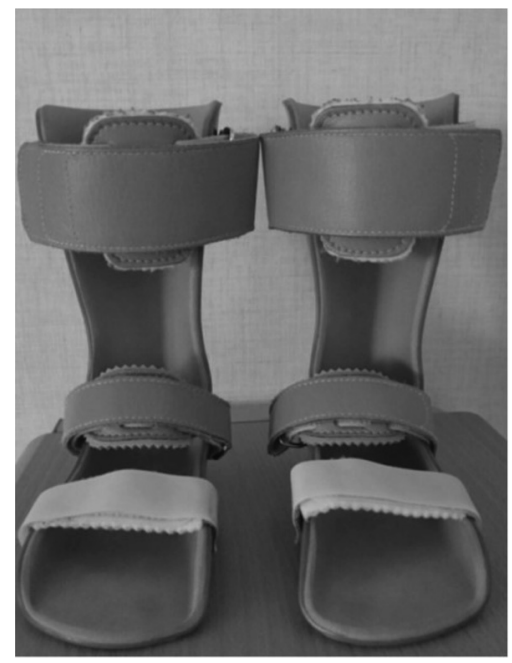

Table 1. Physical characteristics of the subjects and average wear rate of night splints

\begin{tabular}{lccc}
\hline Group & \multicolumn{2}{c}{$\begin{array}{c}\text { Age at the time of Age at the start } \\
\text { implementation } \\
\text { of PSL } \\
\text { (years) }\end{array}$} & $\begin{array}{c}\text { Average wear } \\
\text { rate } \\
\text { (years) }\end{array}$ \\
\hline $\begin{array}{l}\text { Sufficiently-wearing } \\
\text { group (n=6) }\end{array}$ & $5.7 \pm 1.9$ & $6.0 \pm 1.5$ & $93.3 \pm 14.9$ \\
$\begin{array}{l}\text { Insufficiently-wearing } \\
\text { group (n=3) }\end{array}$ & $8.7 \pm 1.7$ & $7.0 \pm 1.4$ & $30.3 \pm 15.8$ \\
\hline
\end{tabular}

Values are expressed as the average \pm standard deviation.

PSL: prednisolone.

Fig. 1. Night splints.

The photograph shows a model of night splints that was implemented at our institution. The splints were made from plastic, and were fixed to the lower legs and ankle joints with belts.

(ROM).

On the other hand, wearing a night splint (Fig. 1), which is an orthosis that is worn on the lower limbs at night, has been shown to be effective for preventing contracture of the ankle joint ${ }^{8}$. Night splints are considered the most effective method for preventing Achilles tendon contracture, which in turn is considered the most significant factor in the inability to walk (due to muscle weakness) $^{9}$. Therefore, in previous studies ${ }^{10,11)}$ and international guidelines ${ }^{12-14)}$, preparing night splints for patients with DMD over 3 years of age is a standard treatment.

One report ${ }^{9}$ ) evaluated the role of night splints for preventing Achilles tendon contracture and maintaining muscle force, as described above. These splints were effective, but no studies have concretely evaluated the maintenance of standing motor function, which is one of the purposes of rehabilitation.

Therefore, in this study, we implemented night splints for patients with DMD who were over 4 years old, according to the protocol of a previous study ${ }^{10)}$. We evaluated the dorsiflexion angles of the ankle and motor function when the participants were in the standing position at one year after splint implementation, and examined how the wearing of night splints affected the motor function of patients with DMD while standing.

\section{SUBJECTS AND METHODS}

We included 9 boys with DMD for whom night splints were implemented (average age \pm standard deviation: $7.9 \pm$ 1.9 years) (Table 1). The average age at the time of night splint implementation was $6.7 \pm 2.3$ years. All the boys had been administered corticosteroids at the average age of $6.3 \pm 1.6$ years. The boys were divided into two groups: those who wore the splint $50 \%$ or more of the time over the one-year period after implementation (the sufficiently-wearing (SW) group), and those who wore it less than $50 \%$ of the time over the same period (the insufficiently-wearing (IW) group). At each monthly physical therapy session, we assessed whether the patient had properly used the night splints. During these sessions, we also confirmed whether or not the patient had properly attached the night splints to his extremities.

The participants were instructed to put on the night splints at bedtime and remove them upon waking every day.

The evaluation was started two months before the implementation of the night splints and ended at one year after the implementation. The patients were evaluated once per month. The dorsiflexion angles of the right and left ankles were measured in units of $5^{\circ}$ using a goniometer. The total scores of the North Star Ambulatory Assessment (NSAA) (on a scale of $0-34)$ were also used. The NSAA is a mobility evaluation method that is used for all ambulatory patients with $\mathrm{DMD}^{15)}$. The evaluation items included measurements of 10-m running and times to stand from the floor, which were studied separately. The 10-m running time (in seconds) was measured three times, and the shortest time was used. The time to stand from the floor (in seconds) was measured once, and that time was used. One physical therapist provided the same physical therapy regimen for all patients. The therapy consisted of ROM exercises for the extremities (for approximately $20 \mathrm{~min}$ ), ROM measurement, NSAA evaluation, and an interview.

From the indicators, changes between the pre-implementation and the one-year-after (it subtracted the value of preimplementation from the value of one-year-after) of both the SW group and IW group were obtained and comparison between 
Table 2. Comparison of the changes between the sufficiently-wearing group and the insufficiently-wearing group for one year

\begin{tabular}{lccc}
\hline & $\begin{array}{c}\text { Sufficiently-wear- } \\
\text { ing group }\end{array}$ & $\begin{array}{c}\text { Insufficiently- } \\
\text { wearing group }\end{array}$ & $\begin{array}{c}\mathrm{p} \\
\text { value }\end{array}$ \\
\hline Right ankle's dorsiflexion angle (degrees) & $3.3 \pm 6.2$ & $-3.3 \pm 6.2$ & \\
Left ankle's dorsiflexion angle (degrees) & $3.3 \pm 5.5$ & $-5.0 \pm 4.1$ & $\mathrm{a}^{*}$ \\
NSAA (scores/34) & $1.8 \pm 1.6$ & $0.5 \pm 4.8$ & \\
10-m running (sec) & $-0.7 \pm 0.7$ & $0.1 \pm 0.8$ & \\
Time to stand from the floor (sec) & $-1.2 \pm 1.4$ & $1.1 \pm 3.0$ & \\
\hline
\end{tabular}

Values are expressed as the average \pm standard deviation.

a:Wilcoxon rank sum test; ${ }^{*} \mathrm{p}<0.05$. NSAA: North Star Ambulatory Assessment.

Table 3. The statistical calculation for each indicator

\begin{tabular}{lccccc}
\hline & $\begin{array}{c}\text { Right ankle's } \\
\text { dorsiflexion } \\
\text { angle }\end{array}$ & $\begin{array}{c}\text { Left ankle's } \\
\text { dorsiflexion } \\
\text { angle }\end{array}$ & NSAA & 10-m running & $\begin{array}{c}\text { Standing from } \\
\text { the floor }\end{array}$ \\
\hline Effect size & 1.06 & 1.71 & 1.67 & 1.06 & 1.15 \\
Statistical power & 0.38 & 0.70 & 0.68 & 0.38 & 0.42 \\
Minimum required sample size & 12 & 6 & 6 & 12 & 11 \\
\hline
\end{tabular}

NSAA: North Star Ambulatory Assessment.

groups was conducted by Wilcoxon rank sum test. Statistical calculation such as the effect size, statistical power and minimum required sample size were calculated by DanielSoper.com ${ }^{16}$. And minimum required sample size was calculated to reach the statistical power level of 0.8. Statistical analysis was performed using the PASW statistics software (version 24.0, SPSS, Inc., Chicago, IL, USA).

This study was approved by the ethics committee of the university, Japan (No. 2804).

\section{RESULTS}

There were 6 patients in the SW group, and their average wearing rate was $93.3 \%$. Five of these boys wore their splint every day. There were three boys in the IW group, and their wearing rates were less than $30.3 \%$. One of these boys only wore his splint for one month during the year (Table 1). There was no significant difference in the patients' ages between the SW and IW groups (Table 1).

Regarding the right ankle dorsiflexion angle, there was no significant difference between the SW and IW groups ( $p=0.230)$ (Table 2). The statistical power was 0.38 and minimum required sample size was 12 (Table 3). Regarding the left ankle dorsiflexion angle, significant improvement was confirmed in the inter-group from changes between the pre-implementation and the one-year-after assessments. $(\mathrm{p}=0.048)$ (Table 2$)$. And statistical power was 0.70 and minimum required sample size was 6 (Table 3 ).

There were no significant differences between the SW and IW groups for NSAA ( $\mathrm{p}=0.065), 10-\mathrm{m}$ running $(\mathrm{p}=0.302)$ and times to stand from the floor $(\mathrm{p}=0.439)$ (Table 2). Their statistical powers were 0.68 (NSAA), $0.38(10-\mathrm{m}$ running) and 0.42 (standing from the floor), and minimum required sample size was 6 (NSAA), 12 (10-m running), and 11 (standing from the floor) (Table 3).

\section{DISCUSSION}

The purpose of this study was to examine whether the night splint wearing rate is associated with the dorsiflexion angles of the ankles and the standing motor function of patients with DMD. In our study, there was a significant difference for changes between the pre-implementation and the one-year-after assessments only in the left ankle's dorsiflexion angle in participants in the SW group, compared with that of participants in the IW group. There was no significant difference of the right ankle's dorsiflexion angle, but in the SW group, the angle of the right leg slightly increased after 1 year, whereas the angle in the IW group tended to decrease slightly. These findings supported the results of previous studies ${ }^{8,9)}$, suggesting that the brace could at least maintain the dorsiflexion angle of the ankle joint. Regarding the NSAA, the scores showed no significant difference in the inter-group from changes between the pre-implementation and the one-year-after assessments. However, since the statistical results showed a significant tendency, it was considered that the tendency to improve NSAA scores was better in the group. 
Regarding the 10-m running and times to stand from the floor, which are NSAA items, there was no significant difference in the inter-group comparison of the SW group from changes between the pre-implementation and the one-year-after assessments. However, we found that both the 10-m running and standing from the floor tended to have shorter times in the SW group than in the IW group, and there were longer times in the IW group than in the SW group. It was limitation of this study that the sample number was very small. From the result of the least significant number, the verification power varies from $38 \%$ to $70 \%$, and it was shown that the minimum sample size was 12 people. Although it was difficult to increase the number of samples in the current study, in future it is necessary to consider the multicenter collaborative research.

We did not include patients for whom night splints were not implemented. We could not compare patients who wore splints with those who did not, and this also may be a limitation of this study. We could not compare these patients for ethical reasons; however, the three patients in the IW group who wore their splint for less than $50 \%$ of the time could be considered control data. These patients did not wear their splints very often due to difficulty in putting them on, sweaty feet and heat, or pain. For patients with pain, the therapist checked the wearing condition and applied towels and socks; but for patients who had trouble putting them on and those with a heat sensation, nothing could be done. These problems may be the demerits of using night splints. However, patients in the SW group showed improvement or a tendency toward improvement in their standing motor function. Therefore, the merits of wearing of night splints were considered to be greater than the demerits. It is necessary for us to communicate the importance of wearing night splints to patients, as well as examine their long-term assessment of motor function with night splints. In future, based on the results of this exploratory study, we would like to develop the hypothetic validation research by increasing the sample size at multicenter collaborative research.

\section{Conflict of interest}

None.

\section{REFERENCES}

1) Bushby K, Finkel R, Birnkrant DJ, et al. DMD Care Considerations Working Group: Diagnosis and management of Duchenne muscular dystrophy, part 1: diagnosis, and pharmacological and psychosocial management. Lancet Neurol, 2010, 9: 77-93. [Medline] [CrossRef]

2) Bushby K, Finkel R, Birnkrant DJ, et al. DMD Care Considerations Working Group: Diagnosis and management of Duchenne muscular dystrophy, part 2 : implementation of multidisciplinary care. Lancet Neurol, 2010, 9: 177-189. [Medline] [CrossRef]

3) Hoffman EP, Brown RH Jr, Kunkel LM: Dystrophin: the protein product of the Duchenne muscular dystrophy locus. Cell, 1987, 51: 919-928. [Medline] [CrossRef]

4) Lovering RM, Porter NC, Bloch RJ: The muscular dystrophies: from genes to therapies. Phys Ther, 2005, 85: 1372-1388. [Medline]

5) Siegel IM: Maintenance of ambulation in Duchenne muscular dystrophy. The role of the orthopedic surgeon. Clin Pediatr (Phila), 1980, 19: 383-388. [Medline] [CrossRef]

6) Seeger BR, Caudrey DJ, Little JD: Progression of equinus deformity in Duchenne muscular dystrophy. Arch Phys Med Rehabil, 1985, 66: 286-288. [Medline]

7) Dooley JM, Gordon KE, MacSween JM: Impact of steroids on surgical experiences of patients with Duchenne muscular dystrophy. Pediatr Neurol, 2010, 43: 173-176. [Medline] [CrossRef]

8) Eagle M: Report on the muscular dystrophy campaign workshop: exercise in neuromuscular diseases Newcastle, January 2002. Neuromuscul Disord, 2002, 12: 975-983. [Medline] [CrossRef]

9) Hyde SA, FlŁytrup I, Glent S, et al.: A randomized comparative study of two methods for controlling Tendo Achilles contracture in Duchenne muscular dystrophy. Neuromuscul Disord, 2000, 10: 257-263. [Medline] [CrossRef]

10) McMillan HJ, Campbell C, Mah JK, Canadian Paediatric Neuromuscular Group: Duchenne muscular dystrophy: Canadian paediatric neuromuscular physicians survey. Can J Neurol Sci, 2010, 37: 195-205. [Medline] [CrossRef]

11) Sejerson T, Bushby K: Standards of care for Duchenne muscular dystrophy: brief TREAT-NMD recommendations. In: Inherited neuromuscular diseases. Netherlands: Springer, 2009, pp 13-21.

12) McKim DA, Road J, Avendano M, et al. Canadian Thoracic Society Home Mechanical Ventilation Committee: Home mechanical ventilation: a Canadian Thoracic Society clinical practice guideline. Can Respir J, 2011, 18: 197-215. [Medline] [CrossRef]

13) Mullender M, Blom N, De Kleuver M, et al.: A Dutch guideline for the treatment of scoliosis in neuromuscular disorders. Scoliosis, 2008, 3: 14. [Medline] [CrossRef]

14) Toussaint M, Davidson Z, Bouvoie V, et al.: Dysphagia in Duchenne muscular dystrophy: practical recommendations to guide management. Disabil Rehabil, 2016, 38: 2052-2062. [Medline] [CrossRef]

15) Mercuri E, Coratti G, Messina S, et al.: Revised North Star ambulatory assessment for young boys with Duchenne muscular dystrophy. PLoS One, 2016, 11: e0160195. [Medline] [CrossRef]

16) DanielSoper.com: Free Statistics Calculators: https://www.danielsoper.com/statcalc/default.aspx. (Accessed Jan. 11, 2018) 